Louisiana State University

LSU Digital Commons

Faculty Publications

Department of Biological Sciences

$1-1-2014$

\title{
Urban microbiomes and urban ecology: How do microbes in the built environment affect human sustainability in cities?
}

Gary M. King

Louisiana State University

Follow this and additional works at: https://digitalcommons.Isu.edu/biosci_pubs

\section{Recommended Citation}

King, G. (2014). Urban microbiomes and urban ecology: How do microbes in the built environment affect human sustainability in cities?. Journal of Microbiology, 52 (9), 721-728. https://doi.org/10.1007/ s12275-014-4364-x

This Article is brought to you for free and open access by the Department of Biological Sciences at LSU Digital Commons. It has been accepted for inclusion in Faculty Publications by an authorized administrator of LSU Digital Commons. For more information, please contact ir@lsu.edu. 


\section{Urban Microbiomes and Urban Ecology: How Do Microbes in the Built Environment Affect Human Sustainability in Cities?}

\author{
Gary M. King* \\ Department of Biological Sciences, Louisiana State University, \\ Baton Rouge, LA 70803, USA \\ (Received Jun 20, 2014 / Revised Aug 6, 2014 / Accepted Aug 6, 2014)
}

Humans increasingly occupy cities. Globally, about $50 \%$ of the total human population lives in urban environments, and in spite of some trends for deurbanization, the transition from rural to urban life is expected to accelerate in the future, especially in developing nations and regions. The Republic of Korea, for example, has witnessed a dramatic rise in its urban population, which now accounts for nearly $90 \%$ of all residents; the increase from about $29 \%$ in 1955 has been attributed to multiple factors, but has clearly been driven by extraordinary growth in the gross domestic product accompanying industrialization. While industrialization and urbanization have unarguably led to major improvements in quality of life indices in Korea and elsewhere, numerous serious problems have also been acknowledged, including concerns about resource availability, water quality, amplification of global warming and new threats to health. Questions about sustainability have therefore led Koreans and others to consider deurbanization as a management policy. Whether this offers any realistic prospects for a sustainable future remains to be seen. In the interim, it has become increasingly clear that built environments are no less complex than natural environments, and that they depend on a variety of internal and external connections involving microbes and the processes for which microbes are responsible. I provide here a definition of the urban microbiome, and through examples indicate its centrality to human function and wellbeing in urban systems. I also identify important knowledge gaps and unanswered questions about urban microbiomes that must be addressed to develop a robust, predictive and general understanding of urban biology and ecology that can be used to inform policy-making for sustainable systems.

Keywords: microbiome, urban, public health, diversity, ecosystem services

\footnotetext{
${ }^{\star}$ For correspondence. E-mail: gkingme@gmail.com
}

\section{Introduction and definitions}

Humans now live predominantly in cities. Whether planned or not, the late 20 th and early 21 st centuries have become an era of urbanization. The global average urban population currently exceeds $53 \%$ of the total population, with a growth rate of $2 \%$ annually (World Bank, http://wdi.worldbank.org/table/3.12). In the United States (US), the urban population has begun to plateau at about $83 \%$, but it continues to grow slowly. Urbanization also accounts for about $83 \%$ of the Republic of Korea's total population (hereafter Korea), although growth to that level occurred much more rapidly than it did in the US. In addition, population densities in Korea's cities are generally much greater than they are in the US; indeed, they are among the highest in the world.

While some have argued that urbanization represents a path towards a sustainable future, largely due to economies of scale, especially for energy, urbanization does not come without problems (Chakarrabarti, 2013). For Korea, as elsewhere this has been evident in concerns about socioeconomic issues, as well as resource availability, water quality, "heat island" exacerbation of global warming, changing patterns of disease and other factors that influence human health (Foster, 2001; Jeong, 2001; Yusuf et al., 2001; Choi et al., 2006; Vlahov et al., 2007; Kim and Kim, 2011). These concerns have led to policies intended to promote some level of deurbanization, however, it remains to be seen to what extent such polices will result in sustainable solutions rather than simply creating new concerns.

Regardless of the policy choices made about urbanization in Korea and elsewhere, it is clear that humans largely will remain in urban systems for the foreseeable future. These systems, sometimes referred to as "built environments", retain the basic features of natural ecosystems though they are quite distinct from them in many respects. For example, specific mass and energy flows characterize the built environment just as they do natural systems along with networks of internal and external connections that determine fundamental properties such as biodiversity, stability, resistance, and resilience.

Among the many constituents of natural systems, microbes are notable for their long recognized critical contributions to biogeochemical functions, e.g., decomposition and nutrient cycling (Fenchel et al., 2012). Many of these functions play important roles in the overall dynamics of urban systems, and some constitute critical "ecosystem services," 
which provide benefits for humans at little or no cost (Bell et al., 2005; Balvanera et al., 2006; Langenheder et al., 2010). For example, nitrification and denitrification have even been exploited extensively for urban wastewater treatment (Bitton, 2011), resulting in substantial economic and health benefits. Nonetheless, many roles of microbes in urban systems have been largely unappreciated. Moreover, when microbes are given any consideration at all, it is often in the context of disease rather than in the benefits they provide. The fact that microbes rarely act as individual populations, but rather act as groups of populations in complex communities, or assemblages, has also been largely unappreciated outside of the discipline of microbial ecology. Many such communities harbor hundreds to thousands of populations that constitute interacting and interdependent networks (Allison and Martiny, 2008). These networks and the services they provide for humans are sensitive to both natural and anthropogenic disturbances, which result in responses that depend on variables such as community composition, species richness and evenness (Yeager et al., 2005; Wittebolle et al., 2009). Identifying and understanding the dynamics of microbial communities in urban environments is thus essential for managing microbes beneficially in the context of urban sustainability.

\section{Microbiome definition and examples}

The term "microbial community" has been used traditionally when referring to assemblages of microbes, but the term "microbiome" has become synonymous with microbial assemblages associated with macroorganisms. In particular, "microbiome" usually refers to Bacteria and Archaea associated with organs (e.g., gut), surfaces of organisms (e.g., epithelia), or organisms as a whole. Joshua Lederberg, a 1958 Nobel Laureate in Physiology or Medicine who described the intimate relationships between humans and microbes, has been credited with using microbiome in its contemporary context (Relman et al., 2009).

During the last 10 years, emphasis on the human microbiome has established biogeographic maps of microbial communities on and within humans of different age, ethnicity, gender, and geographic location (Sears, 2005; Gill et al., 2006; Diaz et al., 2012; Fierer et al., 2012; Faith et al., 2013). Many additional studies have established strong linkages between microbiome composition and activity, and a variety of diseases (Armougom et al., 2009; Larsen et al., 2010; Hu et al., 2011). Yet other studies have shown that some members of the human microbiome contribute beneficially to health in a variety of ways (Fierer et al., 2012).

A large number of studies have also examined microbial associations with plants and animals (Rawls et al., 2004; Thompson et al., 2010; Kelley and Dobler, 2011; Yashiro et al., 2011; King et al., 2012). Some of these have contributed to the design and interpretation of human studies. Together, they have helped transform our understanding of organismal biology by revealing the extent to which multicellular organisms depend on bacterial associates or symbionts for optimal function.

Microbiome research has also addressed assemblages of microbes that are resident on or in a variety of the inanimate objects with which specific organisms come into contact.
Thus, cleaning sponge, shower curtain, kitchen and bathroom surface, cell phone, and computer microbiomes have all been described in an effort to better understand the microbial populations with which humans interact (Feazel et al., 2009; Corsi et al., 2012; Hospodsky et al., 2012; Kelley and Gilbert, 2013; Berg et al., 2014; Fujimura et al., 2014; Kembel et al., 2014; Meadow et al., 2014). These studies have revealed the presence of pathogens in sometimes surprising contexts (Feazel et al., 2009), and documented a surprising level of diversity.

The microbiome concept is extended even further here to the urban scales that define the geographic boundaries within which most people currently spend their time. The urban scale is increasingly important due to the ongoing urbanization of human populations, and concerns about urban sustainability. Extension of the microbiome concept to this scale draws from diverse studies that have recognized urban environments as distinct, complex ecosystems that necessarily include important, but mostly underappreciated roles for microbes (Groffman et al., 2002; Kaye et al., 2006; Pickett et al., 2008; Pouyat et al., 2010).

\section{Urban microbiomes}

What are urban microbiomes? Why do they matter? What do we need to know about them? In the past, methodological and conceptual constraints limited studies on urban microbes mostly to pathogens, pathogen indicators, bio-threat agents and waste treatment systems (Werner et al., 2011; Dobrowski et al., 2014). Some exceptional studies have addressed biogeochemical processes in urban settings (Milesi et al., 2005; Groffman and Pouyat, 2009; Harrison et al., 2011; Bettez and Groffman, 2012), including the role of microbes in the degradation of culturally valuable artifacts and building surfaces (Saiz-Jimenez, 1997; Papida et al., 2000; Herrera and Videla, 2004; Herrera et al., 2004; Webster and May, 2006; Fujii et al., 2010). However, most studies have emphasized individual populations and their effects, and only a few can be considered integrative (Braun et al., 2006; Knapp et al., 2009; Hou et al., 2013).

At present, the majority of observations on urban microbes emphasize building interiors. Regardless, urban microbiomes include microbial assemblages outside of as well as within buildings. Microbiomes occur in associations with building surfaces, roads, streets and other passages; surface and subsurface soils; the phyllosphere of plants; animal and human waste; water distribution systems, streams, drainage systems and other aquatic habitats (Fig. 1).

The urban atmosphere also harbors microbes, even though its populations are transient (Brodie et al., 2007); it acts as both a source and a sink for microbes, and thus contributes to the urban microbiome as a whole (Fig. 1). In addition, the atmosphere provides a "teleconnection" for exchange of microbes between urban and rural systems, and a pathway for the introduction of microbes from distant systems (Bowers et al., 2011). For example, dust and its associated microbes from China's Gobi Desert have been deposited more than $10,000 \mathrm{~km}$ away Los Angeles, California. The impacts of such events on urban microbiomes are essentially unknown, but introductions of pathogens along with beneficial taxa are among them. 


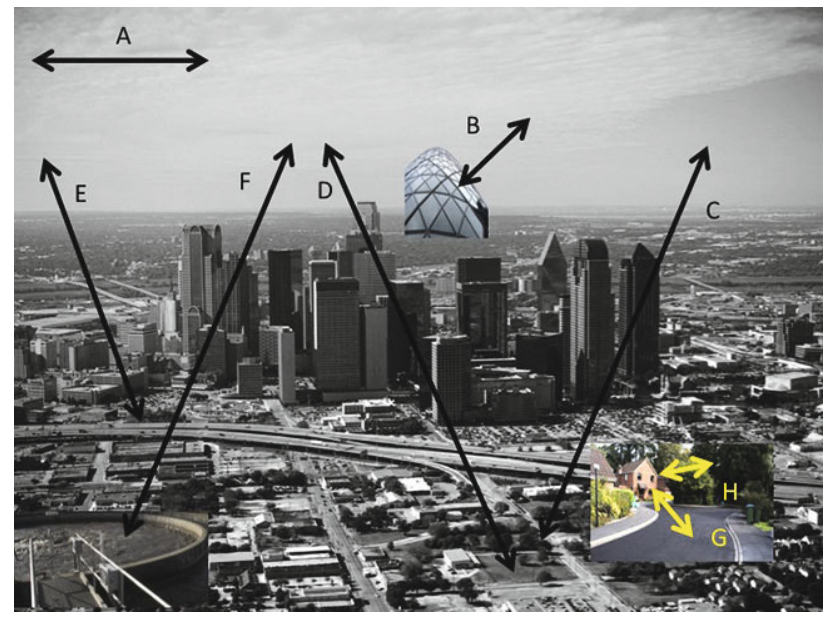

Fig. 1. Conceptual image of an urban microbiome showing some of its many reservoirs of microbes: $A$, the urban atmosphere and its surroundings as a reservoir of microbes transported into and out of urban systems, with long-distance teleconnections; B, building surfaces; C, vegetation; D, open grounds; E, streets and roadways; F, waste treatment systems; G, H connections between indoor and exterior microbiomes.

Thus, urban microbiomes can be defined very simply as the vast and diverse assemblages of resident and transient microbes that occur on or within the numerous habitats that comprise urban systems. Detailed characterizations of these assemblages are now conceivable using "next-generation" approaches for metagenetic and metagenomic sequencing. However, this capability begs several important questions: why do urban microbiomes matter? why would one want to characterize them in the first place? are there connections with new initiatives in urban sustainability, e.g., urban agriculture?

\section{Urban microbiomes: why do they matter?}

The significance of urban microbiomes derives from many factors, some of which involve human wellbeing directly (Barnes et al., 2011). For example, microbial communities in waste treatment systems have contributed greatly to the substantial gains in public health that have occurred since about 1900. Indeed, modern urban communities are inconceivable without advanced microbial waste treatment.

Urban microbiomes also affect human wellbeing indirectly. For instance, some microbes in urban environments produce greenhouse gases (e.g., nitrous oxide, $\mathrm{N}_{2} \mathrm{O}$, and nitric oxide, NO) that contribute to global warming and tropospheric ozone formation, both of which affect health adversely (Kaye et al., 2004; Towsend-Small et al., 2011), while other microbes contribute to pollutant detoxification (Kolvenbach et al., 2014). Human life in urban systems is therefore inextricably linked to microbes, the importance of which is summarized briefly below with several examples.

\section{Microbial biomass and diversity}

In undisturbed terrestrial systems, soil microbial biomass typically accounts for a substantial fraction of total non- plant biomass (Tate, 2000). Although inventories have not yet been reported for urban systems, the relatively small amount of exposed soil surface in them suggests that microbial biomass might be modest at best, and distributed very differently than in undisturbed systems. The potential consequences of different distributions are unknown; likewise the extent to which soil beneath built surfaces contributes to the biogeochemical "footprint" of urban systems is also unknown.

Nonetheless, microbes undoubtedly constitute the greatest reservoir of urban species and genetic biodiversity, exceeding the diversity of all urban plants and animals combined, with thousands of microbial species per gram of soil, and this does not even consider microbes that colonize or are otherwise associated with plants and animals themselves. The diversity of urban microbes includes species that provide major ecosystems services (e.g., waste treatment, pollutant biodegradation, nitrogen fixation) from which humans benefit, as well as species that have adverse impacts (e.g., plant and animal pathogenesis and building deterioration). Reasonably complete inventories exist for plant and animal diversity in urban systems, but comparable assessments for microbes are lacking and should be developed using the power of nextgeneration sequencing platforms, along with analyses of microbiome variability in space and time.

\section{Microbes and biogeochemical transformations}

Like their counterparts in unmanaged systems, microbes mediate numerous biogeochemical processes that affect mass and energy flows within urban systems, and mass and energy exchanges between urban systems and their surroundings. Many of these processes occur during waste treatment, which exploits a wide range of microbes to transform trace metals and pollutants, along with carbon-, nitrogen-, and phosphorous-containing compounds, in systems designed to promote human and environmental health (Bitton, 2011). Waste treatment systems have typically focused on microbes and microbial processes that reduce organic carbon concentrations through hydrolysis, fermentation and respiration, and eliminate fixed nitrogen from effluents, often with coupled systems for nitrification and denitrification (Bitton, 2011). In some cases, waste treatment also optimizes production and recovery of biogenic methane or bioelectricity as renewable sources of energy (McCarty et al., 2011), and there is a growing need to optimize phosphorus recovery during waste treatment, since phosphorus limitation for fertilizer use is a serious emerging global-scale problem (Cordell et al., 2008). Bacteria, including members of the genus Accumulibacter, play important roles in phosphorous removal during waste treatment (Seviour et al., 2003; Peterson et al., 2008), and could prove particularly important for phosphorus management in the future.

Other important microbial processes occur in urban soils, riparian systems and structures engineered for controlling water movement (e.g., storm runoff; Arango et al., 2008; Cadenasso et al., 2008; Harrison et al., 2011; Li et al., 2014). Denitrification is particularly significant, because it can limit exports to receiving systems (e.g., inland and coastal waters) of nitrate arising from nitrogen mismanagement and pollution (Klocker et al., 2009; Harrison et al., 2011). However, 
denitrification also forms $\mathrm{N}_{2} \mathrm{O}$, which leads to an increase in the global warming "footprint" of urban systems. While rigorous management of nitrogen use in urban systems might represent the primary mechanism for controlling $\mathrm{N}_{2} \mathrm{O}$ emissions, a deeper understanding of the relevant microbial populations, their activities and controls is also essential.

\section{Microbes and water distribution systems}

Microbial communities in water distribution systems have become a focal point for increased research, since "premise plumbing" systems (i.e., the water distribution systems of buildings) are now known to harbor distinct microbiomes (Wang et al., 2013). Numerous opportunistic pathogens, including various mycobacteria, Pseudomonas, Legionella and protozoans such as Acanthamoeba, occur in premise plumbing, from which they can contribute to outbreaks of waterborne diseases. For example, the protozoa Naegleria fowleri, which causes a typically fatal primary amebic meningoencephalitis, has recently been found in premise plumbing in Louisiana, USA, even though its principle habitats have been open, warm surface waters.

Although much remains unknown about the microbiomes of premise plumbing, Wang et al. (2013) have suggested that they might be manipulated using a form of probiotic treatment to limit opportunistic pathogens. To accomplish this successfully will require new research programs leading to a level of understanding comparable to that currently emerging for the human gut microbiome. Success will also depend on greater recognition of the integral roles that microbes play in all built systems, as well as recognition of our routine and intimate associations with those microbes.

\section{Exposures to microbes and consequences}

Humans-microbe interactions, both direct and indirect, occur routinely in urban environments due to the ubiquity of microbes. Typically such interactions have no obvious consequences. However, exposures to some airborne microbes might have beneficial consequences for immunological fitness based on recent research results. In particular, lower incidences of asthma have been associated with exposures to microbes in rural rather than urban atmospheres (Riedler et al., 2001; Ege et al., 2011; Illi et al., 2012). This outcome might be due to many factors, including the concentration and diversity of airborne microbes and durations of exposure. Regardless, the results indicate that increased urbanization could be associated with future increases in asthma if protective antigen exposures decrease. Interestingly, the protective benefits of rural atmospheres have been attributed to farm environments and activities. This suggests that urban agriculture might provide protective benefits if agricultural activity is incorporated appropriately within urban systems that promote human exposure to suitable suites of antigens.

\section{Microbial interactions with plants}

Soil microbes play profoundly important roles in plant production, and thus must be considered in initiatives to develop sustainable urban agriculture. Soil microbes complete with plants for nitrogen and other nutrients, but they can also promote growth by facilitating nutrient uptake through symbiotic or associative relationships that have been thoroughly documented for many natural and agricultural systems (Tate, 2000). Plant growth-promoting rhizobacteria (PGPR) also aid in defenses against disease by regulating some plant pathogens and contributing to "induced systemic resistance" (Faure et al., 2008; Belimov et al., 2009; Doornbos et al., 2011; Hassan and Mathesius, 2012; Carvalhais et al., 2013).

In addition, urban soils are usually degraded relative to agricultural and natural soils due to the presence of toxic metals and organics (e.g., copper, lead, polycyclic aromatic hydrocarbons), which can limit plant productivity. In some cases, soil microbes have been successfully used to enhance metal and organic phytoremediation in brownfield and other contaminated soils (Di Gregorio et al., 2006; Gerhardt et al., 2009). Microbially enhanced phytoremediation might thus prove generally useful as a pre-treatment to improve urban soil quality for agricultural and other applications. Targeted selection of plants and bacterial inoculants, along with strategies to enhance naturally occurring microbial biodegradation, could increase the inventory of agriculturally suitable soils with little to moderate cost. Similar approaches could also be used to "condition" microbial communities to optimize and sustain urban production, but this will require new knowledge about urban soil microbes.

\section{Urban microbiomes: what do we need to know?}

Analyses of urban microbiomes have only just begun. Recent studies have characterized urban atmospheres, waste treatment systems and building interiors (Brodie et al., 2007; Cai et al., 2014; Kembel et al., 2014), yielding new and unanticipated insights about the composition and distributions of bacteria, including possibilities for improving health outcomes through microbiome-informed building design (Kembel et al., 2014). However, these studies clearly represent only the first stages of much larger efforts to define the unique characteristics of urban ecosystems as well as characteristics they share with unmanaged systems. Some of the knowledge gaps and emerging questions about urban microbiomes are summarized below.

A. 1. Where in urban systems are microbes most abundant (e.g., the atmosphere, plants, soils, humans, and other animals, waste treatment systems, exteriors and interiors of buildings) and how does the relative importance of microbial reservoirs vary with space and time within and among urban systems?

\section{How do the individual populations within urban microbiomes interact over space and time?}

The compositions and dynamics of urban microbiomes have not yet been explored in detail, and thus represent large knowledge gaps. Soils might represent the greatest concentration of genetic and functional diversity in urban microbiomes, but this assumption has not been evaluated empirically, and might not prove true across and among 
cityscapes as soil distributions and masses change. Although interactions through the atmosphere of indoor and outdoor microbiomes are now being explored, there are likely other modes for interaction; identifying and analyzing such interactions is essential for developing explanatory and predictive models of microbial distributions and determining the factors that contribute to changes in them.

B. 1. For what important biological, ecological and biogeochemical functions are urban microbiomes responsible? How do they differ from the functions of microbiomes in unmanaged systems; how do they vary across space and time, and what controls their expression?

2. Can microbiomes of building surfaces and other structures be managed to control deterioration or weathering, or to promote pollutant remediation?

While some inferences can be derived from species composition inventories, in general little is known about urban microbiome biogeochemical functions. A few important functions (e.g., denitrification and methane oxidation) have been documented in some specific cases using targeted assays, but at present functions are often based on the presence of phylogenetic marker genes (e.g., 16S rRNA genes) that provide only broad indications of potential, and that have proven unreliable for detailed predictions involving specific taxa. Thus, the possibility of manipulating microbiomes or their functions to achieve particular goals, e.g., to control deterioration of building materials, remains a somewhat distant goal. Nonetheless, rapid gains in high throughput sequencing along with lower costs and improvements in sequence data analysis suggest that urban microbiome function can be addressed using the omics toolkit along with other targeted assays. Implementation of these studies could be profitably integrated with parallel studies on the use of nanomaterials to produce pollutant degrading building surfaces (Chen and Poon, 2009; Quagliarini et al., 2012), a topic for which there is considerable interest. Do surface biofilms impede the performance of such materials? Are they inhibitory to microbial colonization? Can one be manipulated to affect performance of the other? Clearly there are many unanswered questions and numerous research opportunities.

\section{1. How do urban microbiomes interact with the mi- crobiomes of surrounding regions, and what mecha- nisms are involved?}

Neither urban systems nor their microbiomes exist in isolation. Exchanges between urban systems and the surroundings in which they are embedded obviously can occur via the atmosphere. Indeed, the importance of short- and longrange atmospheric transport for microbe dispersal is well documented. However, other transport mechanisms also disperse microbes, though their relative significance is unknown, and they likely vary among urban systems and for specific microbial groups. Riverine transport, for instance, might be important as a source of some bacteria in some urban systems (e.g., Busan, Chungju, and Seoul), but play smaller roles in others (e.g., Cheongju, Daejeon, and Suwon). Microbial transport directly and indirectly due to fluxes of humans, vehicles and plants and animals into and out of cities might also be important in many cases.

\section{1. Can the potential health benefits from exposure to rural-agroecosystem microbial aerosols be reproduced in urban environments at scales large enough to benefit urban populations?}

Asthma is a growing problem in Korea as it is elsewhere (Cho et al., 2006). Although not fully understood, a number of recent observations suggest that the incidence of asthma can be reduced by exposure to microbes present in rural atmospheres, particularly those that are associated with agriculture, and especially animal production. Whether or not such exposures and their potential health benefits can be reproduced in urban environments is unknown at present. However, with rising interest in Korean cities for urban agriculture, including "vertical farming" (http://www.hani.co. kr/arti/english_edition/e_national/588995.html), it might be possible to recreate some of the beneficial exposures that occur in rural systems, thereby adding a new dimension to urban food production. Recreating beneficial exposures will require a significant and multidisciplinary research effort, but it is worth recalling that urbanization is a recent phenomenon in human history, and that human immunological systems evolved in a very different context with exposures to different suites of antigens than occur in urban environments. Reproducing some of those exposures could contribute to improved urban health outcomes and promote urban sustainability.

\section{Summary}

Microbes are both the foundation and fabric of all life including human life. Thus, individual microbes have long been a focus of health concerns, and they have also long been exploited beneficially (e.g., Streptomyces griseus for drug production). Nonetheless, microbes exist naturally in complex communities, or microbiomes, and it is in this context that their significance arises. Whether in the human gut or broadly distributed across cityscapes, microbiomes play profoundly important roles in the activities and functions of the hosts and systems they inhabit. The composition and dynamics of urban microbiomes are largely unknown at present, but it is clear that they contribute basic services that make urban life possible. It is also clear that a greater understanding of urban microbiomes is essential for promoting urban sustainability and ensuring the success of rapidly expanding initiatives such as urban agriculture. 


\section{References}

Allison, S.D. and Martiny, J.B. 2008. Colloquium paper: resistance, resilience, and redundancy in microbial communities. Proc. Natl. Acad. Sci. USA 105 Suppl 1, 11512-11519.

Arango, C.P., Tank, J.L., Johnson, L.T., and Hamilton, S.K. 2008. Assimilatory uptake rather than nitrification and denitrification determines nitrogen removal patterns in streams of varying land use. Limnol. Oceanogr. 53, 2558-2572.

Armougom, F., Henry, M., Vialettes, B., Raccah, D., and Raoult, D. 2009. Monitoring bacterial community of human gut microbiota reveals an increase in Lactobacillus in obese patients and Methanogens in anorexic patients. PLoS ONE 4, e7125.

Balvanera, P., Pfisterer, A.B., Buchmann, N., He, J.S., Nakashizuka, T., Raffaelli, D., and Schmid, B. 2006. Quantifying the evidence for biodiversity effects on ecosystem functioning and services. Ecol. Lett. 9, 1146-1156.

Barnes, I., Duda, A., Pybus, O.G., and Thomas, M.G. 2011. Ancient urbanization predicts genetic resistance to tuberculosis. Evolution 65, 842-848.

Belimov, A.A., Dodd, I.C., Hontzeas, N., Theobald, J.C., Safronova, V.I., and Davies, W.J. 2009. Rhizosphere bacteria containing 1-aminocyclopropane-1-carboxylate deaminase increase yield of plants grown in drying soil via both local and systemic hormone signalling. New Phytol. 181, 413-423.

Bell, T., Newman, J.A., Silverman, B.W., Turner, S.L., and Lilley, A.K. 2005. The contribution of species richness and composition to bacterial services. Nature 436, 1157-1160.

Berg, G., Mahnert, A., and Moissl-Eichinger, C. 2014. Beneficial effects of plant-associated microbes on indoor microbiomes and human health? Front Microbiol. 5, 15.

Bettez, N.D. and Groffman, P.M. 2012. Denitrification potential in stormwater control structures and natural riparian zones in an urban landscape. Environ. Sci. Technol. 46, 10909-10917.

Bitton, G. 2011. Wastewater microbiology, $4^{\text {th }}$ ed. John Wiley and Sons, Hoboken, NJ, USA.

Bowers, R.M., McLetchie, S., Knight, R., and Fierer, N. 2011. Spatial variability in airborne bacterial communities across land-use types and their relationship to the bacterial communities of potential source environments. ISME J. 5, 601-612.

Braun, B., Böckelmann, U., Grohmann, E., and Szewzyk, U. 2006. Polyphasic characterization of the bacterial community in an urban soil profile with in situ and culture-dependent methods. Appl. Soil Ecol. 31, 267-279.

Brodie, E.L., DeSantis, T.Z., Parker, J.P.M., Zubietta, I.X., Piceno, Y.M., and Andersen, G.L. 2007. Urban aerosols harbor diverse and dynamic bacterial populations. Proc. Natl. Acad. Sci. USA 104, 299-304.

Cadenasso, M.L., Pickett, S.T., Groffman, P.M., Band, L.E., Brush, G.S., Galvin, M.F., Grove, J.M., Hagar, G., Marshall, V., McGrath, B.P., and et al. 2008. Exchanges across land-water-scape boundaries in urban systems: strategies for reducing nitrate pollution. Ann. NY Acad. Sci. 1134, 213-232.

Cai, L., Feng, J., and Zhang, T. 2014. Tracking human sewage microbiome in a municipal wastewater treatment plant. Appl. Microbiol. Technol. 98, 3317-3326.

Carvalhais, L.C., Dennis, P.G., Badri, D.V., Tyson, G.W., Vivanco, J.M., and Schenk, P.M. 2013. Activation of the jasmonic acid plant defence pathway alters the composition of rhizosphere bacterial communities. PLoS ONE 8, e56457.

Chakrabarti, V. 2013. A country of cities: a manifesto for urban America, p. 251. Metropolis Books, New York, USA.

Chen, J. and Poon, C.S. 2009. Photocatalytic cementitious materials: influence of the microstructure of cement paste on photocatalytic pollution degradation. Environ. Sci. Technol. 43, 8948-8952.

Cho, S.H., Park, H.W., and Rosenberg, D.M. 2006. The current status of asthma in Korea. J. Korean Med. Sci. 21, 181-187.

Choi, Y.J., Cho, Y.M., Park, C.K., Jang, H.C., Park, K.S., Kim, S.Y., and Lee, H.K. 2006. Rapidly increasing diabetes-related mortality with socio-environmental changes in South Korea during the last two decades. Diabetes Res. Clin. Pract. 74, 295-300.

Cordell, D., Drangert, J.O., and White, S. 2008. The story of phosphorus: Global food security and food for thought. Glob. Environ. Change 19, 292-305.

Corsi, R.L., Kinney, K.A., and Levin, H. 2012. Microbiomes of built environments: 2011 symposium highlights and workgroup recommendations. Indoor Air 22, 171-172.

Di Gregorio, S., Barbafieri, M., Lampis, S., Sanangelantoni, A.M., Tassi, E., and Vallini, G. 2006. Combined application of Triton X-100 and Sinorhizobium sp. Pb002 inoculum for the improvement of lead phytoextraction by Brassica juncea in EDTA amended soil. Chemosphere 63, 293-299.

Diaz, P.I., Dupuy, A.K., Abusleme, L., Reese, B., Obergfell, C., Choquette, L., Dongari-Bagtzoglou, A., Peterson, D.E., Terzi, E., and Strausbaugh, L.D. 2012. Using high throughput sequencing to explore the biodiversity in oral bacterial communities. Mol. Oral Microbiol. 27, 182-201.

Dobrowsky, P.H., De Kwaadsteniet, M., Cloete, T.E., and Khan, W. 2014. Distribution of indigenous bacterial pathogens and potential pathogens associated with roof-harvested rainwater. Appl. Environ. Microbiol. 80, 2307-2316.

Doornbos, R.F., Loon, L.C., and Bakker, P.A.H.M. 2011. Impact of root exudates and plant defense signaling on bacterial communities in the rhizosphere. A review. Agron. Sustain. Devel. 32, 227-243.

Ege, M.J., Mayer, M., Normand, A.C., Genuneit, J., Cookson, W.O., Braun-Fahrländer, C., Heederik, D., Piarroux, R., von Mutius, E., and GABRIELA Transregio 22 Study Group. 2011. Exposure to environmental microorganisms and childhood asthma. New Engl. J. Med. 364, 701-709.

Faith, J.J., Guruge, J.L., Charbonneau, M., Subramanian, S., Seedorf, H., Goodman, A.L., Clemente, J.C., Knight, R., Heath, A.C., Leibel, R.L., and et al. 2013. The long-term stability of the human gut microbiota. Science 341, 6141. DOI: 10.1126/science. 1237439.

Faure, D., Vereecke, D., and Leveau, J.H.J. 2008. Molecular communication in the rhizosphere. Plant Soil 321, 279-303.

Feazel, L.M., Baumgartner, L.K., Peterson, K.L., Frank, D.N., Harris, J.K., and Pace, N.R. 2009. Opportunistic pathogens enriched in showerhead biofilms. Proc. Natl. Acad. Sci. USA 106, 16393-16399.

Fenchel, T., King, G.M., and Blackburn, T.H. 2012. Bacterial biogeochemistry: the ecophysiology of mineral cycling, p. 303. Academic Press, London, UK.

Fierer, N., Fierer, N., Ferrenberg, S., Flores, G.E., González, A., Kueneman, J., Legg, T., Lynch, R.C., McDonald, D., Mihaljevic, J.R., and et al. 2012. From animalcules to an ecosystem: application of ecological concepts to the human microbiome. Ann. Rev. Ecol. Evol. Syst. 43, 137-155.

Foster, S.S.D. 2001. The interdependence of groundwater and urbanisation in rapidly developing cities. Urban Water 3, 185-192.

Fujii, Y., Fujiwara, Y., Kigawa, R., Suda, T., and Suzuki, Y. 2010. Characteristics and diagnosing technology of biodegradation in wooden historical buildings: a case study on Amida-do in Higashi Hongan-ji Temple in Kyoto. World Conf Timber Engineer.

Fujimura, K.E., Demoor, T., Rauch, M., Faruqi, A.A., Jang, S., Johnson, C.C., Boushey, H.A., Zoratti, E., Ownby, D., Lukacs, N.W., and et al. 2014. House dust exposure mediates gut microbiome Lactobacillus enrichment and airway immune defense against allergens and virus infection. Proc. Natl. Acad. Sci. USA 111, 805-810.

Gerhardt, K.E., Huang, X.D., Glick, B.R., and Greenberg, B.M. 2009. Phytoremediation and rhizoremediation of organic soil contaminants: Potential and challenges. Plant Sci. 176, 20-30. 
Gill, S.R., Pop, M., DeBoy, R.T., Eckburg, P.B., Turnbaugh, P.J., Samuel, B.S., Gordon, J.I., Relman, D.A., Fraser-Liggett, C.M., and Nelson, K.E. 2006. Metagenomic analysis of the human gut distal microbiome. Science 312, 1355-1359.

Groffman, P.M., Boulware, N.J., Zipperer, W.C., Pouyat, R.V., Band, L.E., and Colosimo, M.F. 2002. Soil nitrogen cycle processes in urban riparian zones. Environ. Sci. Technol. 36, 4547-4552.

Groffman, P.M. and Pouyat, R.V. 2009. Methane uptake in urban forests and lawns. Environ. Sci. Technol. 43, 5229-5235.

Harrison, M.D., Groffman, P.M., Mayer, P.M., Kaushal, S.S., and Newcomer, T.A. 2011. Denitrification in alluvial wetlands in an urban landscape. J. Environ. Qual. 40, 634.

Hassan, S. and Mathesius, U. 2012. The role of flavonoids in rootrhizosphere signalling: opportunities and challenges for improving plant-microbe interactions. J. Exp. Bot. 63, 3429-3444.

Herrera, L.K., Arroyave, C., Guiamet, P., de Saravia, S.G., and Videla, H. 2004. Biodeterioration of peridotite and other constructional materials in a building of the Colombian cultural heritage. Int. Biodeterior. Biodegrad. 54, 135-141.

Herrera, L.K. and Videla, H.A. 2004. The importance of atmospheric effects on biodeterioration of cultural heritage constructional materials. Int. Biodeterior. Biodegrad. 54, 125-134.

Hospodsky, D., Qian, J., Nazaroff, W.W., Yamamoto, N., Bibby, K., Rismani-Yazdi, H., and Peccia, J. 2012. Human occupancy as a source of indoor airborne bacteria. PLOS ONE 7, e34867.

Hou, J., Cao, X., Song, C., and Zhou, Y. 2013. Predominance of ammonia-oxidizing archaea and nirK-gene-bearing denitrifiers among ammonia-oxidizing and denitrifying populations in sediments of a large urban eutrophic lake (Lake Donghu). Can. J. Microbiol. 59, 456-464.

Hu, S., Dong, T.S., Dalal, S.R., Wu, F., and Bissonnette, M. 2011. The microbe-derived short chain fatty acid butyrate targets miRNAdependent p21 gene expression in human colon cancer. PLoS ONE 6, e16221.

Illi, S., Depner, M., Genuneit, J., Horak, E., Loss, G., Strunz-Lehner, C., Büchele, G., Boznanski, A., Danielewicz, H., and Cullinan, P. 2012. Protection from childhood asthma and allergy in Alpine farm environments-the GABRIEL Advanced Studies. J. Allergy Clin. Immunol. 129, 1470-1477.

Jeong, C.H. 2001. Effect of land use and urbanization on hydrochemistry and contamination of groundwater from Taejon area, Korea. J. Hydrol. 253, 194-220.

Kaye, J.P., Burke, I.C., Mosier, A.R., and Guerschman, J.P. 2004. Methane and nitrous oxide fluxes from urban soils to the atmosphere. Ecol. Appl. 14, 975-981.

Kaye, J.P., Groffman, P.M., Grimm, N.B., Baker, L.A., and Pouyat, R.V. 2006. A distinct urban biogeochemistry? Trends Ecol. Evol. 21, 192-199.

Kelley, S.T. and Dobler, S. 2011. Comparative analysis of microbial diversity in Longitarsus flea beetles (Coleoptera: Chrysomelidae). Genetica 139, 541-550.

Kelley, S.T. and Gilbert, J.A. 2013. Studying the microbiology of the indoor environment. Genome Biol. 14, 202.

Kembel, S.W., Meadow, J.F., O'Connor, T.K., Mhuireach, G., Northcutt, D., Kline, J., Moriyama, M., Brown, G.Z., Bohannan, B.J.M., and Green, J.L. 2014. Architectural design drives the biogeography of indoor bacterial communities. PLoS ONE 9, e87093.

Kim, M.K. and Kim, S. 2011. Quantitative estimates of warming by urbanization in South Korea over the past 55 years (1954-2008). Atmospheric Environment 45, 5778-5783.

King, G.M., Judd, C., Kuske, C.R., and Smith, C. 2012. Analysis of stomach and gut microbiomes of the eastern oyster (Crassostrea virginica) from Coastal Louisiana, USA. PLoS ONE 7, e51475.

Klocker, C.A., Kaushal, S.S., Groffman, P.M., Mayer, P.M., and Morgan, R.P. 2009. Nitrogen uptake and denitrification in restored and unrestored streams in urban Maryland, USA. Aquat. Sci. 71, 411-424.
Knapp, C.W., Dodds, W.K., Wilson, K.C., O'Brien, J.M., and Graham, D.W. 2009. Spatial heterogeneity of denitrification genes in a highly homogenous urban stream. Environ. Sci. Technol. 43, 4273-4279.

Kolvenbach, B.A., Helbling, D.E., Kohler, H.P., and Corvini, P.F. 2014. Emerging chemicals and the evolution of biodegradation pathways and capacities in bacteria. Curr. Opin. Biotechnol. 27, 8-14.

Langenheder, S., Bulling, M.T., Solan, M., and Prosser, J.I. 2010. Bacterial biodiversity-ecosystem functioning relations are modified by environmental complexity. PLOS ONE 5, e10834.

Larsen, N., Vogensen, F.K., van den Berg, F.W.J., Nielsen, D.S., Andreasen, A.S., Pedersen, B.K., Al-Soud, W.A., Sørensen, S.J., Hansen, L.H., and Jakobsen, M. 2010. Gut microbiota in human adults with type 2 diabetes differs from non-diabetic adults. PLoS ONE 5, e9085.

Li, S., Deng, H., Rensing, C., and Zhu, Y.G. 2014. Compaction stimulates denitrification in an urban park soil using $(15) \mathrm{N}$ tracing technique. Environ. Sci. Pollut. Res. Int. 21, 3783-3791.

McCarty, P.L., Bae, J., and Kim, J. 2011. Wastewater treatment as a net energy producer-can this be achieved? Environ. Sci. Technol. 45, 7100-7106.

Meadow, J.F., Altrichter, A.E., Kembel, S.W., Moriyama, M., O'Connor, T.K., Womack, A.M., Brown, G.Z., Green, J.L., and Bohannan, B.J. 2014. Bacterial communities on classroom surfaces vary with human contact. Microbiome 2, 7 .

Milesi, C., Running, S.W., Elvidge, C.D., Dietz, J.B., Tuttle, B.T., and Nemani, R.R. 2005. Mapping and modeling the biogeochemical cycling of turf grasses in the United States. Environ. Manage. 36, 426-438.

Papida, S., Murphy, W., and May, E. 2000. Enhancement of physical weathering of building stones by microbial populations. Int. Biodeterior. Biodegrad. 46, 305-317.

Peterson, S.B., Warnecke, F., Madejska, J., McMahon, K.D., and Hugenholtz, P. 2008. Environmental distribution and population biology of Candidatus accumulibacter, a primary agent of biological phosphorus removal. Environ. Microbiol. 10, 2692-2703.

Pickett, S.T., Cadenasso, M.L., Grove, J.M., Groffman, P.M., Band, L.E., Boone, C.G., Burch, W.R. Jr., Grimmond, C.S.B., Hom, J., Jenkins, J.C., and et al. 2008. Beyond urban legends: an emerging framework of urban ecology, as illustrated by the Baltimore Ecosystem Study. BioScience 58, 139-150.

Pouyat, R.V., Szlavecz, K., Yesilonis, I.D., Groffman, P.M., and Schwarz, K. 2010. Chemical, physical and biological characterization of urban soils. Agronomy Monograph. 55 doi:10.2134/ agronmonogr55.c7.

Quagliarini, E., Bondioli, F., Goffredo, G.B., Cordoni, C., and Munafò, P. 2012. Self-cleaning and de-polluting stone surfaces: TiO2 nanoparticles for limestone. Construct. Build. Mater. 37, 51-57.

Rawls, J.F., Samuel, B.S., and Gordon, J.I. 2004. Gnotobiotic zebrafish reveal evolutionarily conserved responses to the gut microbiota. Proc. Natl. Acad. Sci. USA 101, 4596-4601.

Relman, D.A., Hamburg, M.A., Choffnes, E.R., and Mack, A. 2009. Microbial evolution and co-adaptation: a tribute to the life and scientific legacies of Joshua Lederberg, p. 339. National Academies Press, Washington, DC, USA.

Riedler, J., Braun-Fahrländer, C., Eder, W., Schreuer, M., Waser, M., Maisch, S., Carr, D., Schierl, R., Nowak, D., von Mutius, E., and ALEX Study Team. 2001. Exposure to farming in early life and development of asthma and allergy: a cross-sectional survey. Lancet 358, 1129-1133.

Saiz-Jimenez, C. 1997. Biodeterioration vs biodegradation: the role of microorganisms in the removal of pollutants deposited on historic buildings. Int. Biodeterior. Biodeg. 40, 225-232.

Sears, C.L. 2005. A dynamic partnership: celebrating our gut flora. Anaerobe 11, 247-251. 
Seviour, R.J., Mino, T., and Onuki, M. 2003. The microbiology of biological phosphorus removal in activated sludge systems. FEMS Microbiol. Rev. 27, 99-127.

Tate, R.L., III. 2000. Soil microbiology, $2^{\text {nd }}$ ed. John Wiley and Sons, New York, N.Y., USA.

Thompson, C.L., Hofer, M.J., Campbell, I.L., and Holmes, A.J. 2010. Community dynamics in the mouse gut microbiota: a possible role for IRF9-regulated genes in community homeostasis. PLoS ONE 5, e10335.

Townsend-Small, A., Pataki, D.E., Czimczik, C.I., and Tyler, S.C. 2011. Nitrous oxide emissions and isotopic composition in urban and agricultural systems in southern California. J. Geophys. Res. 116. Doi: $10.1029 / 2010 j g 001494$.

Vlahov, D., Freudenberg, N., Proietti, F., Ompad, D., Quinn, A., Nandi, V., and Galea, S. 2007. Urban as a determinant of health. J. Urban Health 84, 16-26.

Wang, H., Edwards, M.A., Falkinham, J.O., III, and Pruden, A. 2013. Probiotic approach to pathogen control in premise plumbing systems? A review. Environ. Sci. Technol. 47, 10117-101128.

Webster, A. and May, E. 2006. Bioremediation of weathered-building stone surfaces. Trends Biotechnol. 24, 255-260.
Werner, J.J., Knights, D., Garcia, M.L., Scalfone, N.B., Smith, S., Yarasheski, K., Cummings, T.A., Beers, A.R., Knight, R., and Angenent, L.T. 2011. Bacterial community structures are unique and resilient in full-scale bioenergy systems. Proc. Natl. Acad. Sci. USA 108, 4158-4163.

Wittebolle, L., Marzorati, M., Clement, L., Balloi, A., Daffonchio, D., Heylen, K., Vos, P. De, Verstraete, W., and Boon, N. 2009. Initial community evenness favours functionality under selective stress. Nature 458, 623-626.

Yashiro, E., Spear, R.N., and McManus, P.S. 2011. Culture-dependent and culture-independent assessment of bacteria in the apple phyllosphere. J. Appl. Microbiol. 110, 1284-1296.

Yeager, C.M., Northup, D.E., Grow, C.C., Barns, S.M., and Kuske, C.R. 2005. Changes in nitrogen-fixing and ammonia-oxidizing bacterial communities in soil of a mixed conifer forest after wildfire. Appl. Environ. Microbiol. 71, 2713-2722.

Yusuf, S., Reddy, S., Ounpuu, S., and Anand, S. 2001. Global burden of cardiovascular diseases: Part I: General considerations, the epidemiologic transition, risk factors, and impact of urbanization. Circulation 104, 2746-2753. 